\title{
Assessing the effect of standardized cost systems on financial performance. A difference-in-differences approach for hospitals according to their technological level
}

\begin{abstract}
Promoting the improvement of standardized cost systems (CS) is one of the measures available to health policy makers for the purpose of improving efficiency in hospitals over the long-term. Nevertheless, very few studies evaluate the relationship between alternative CS and the costs really incurred. We use data from 242 hospitals of the Spanish National Health Service (NHS) between 2010 and 2013 in order to explore the determinants of the cost per adjusted patient day, using a difference-in-differences approach where the treatment is the implementation of an advanced CS. We also investigate if the association between advanced CS and unit cost is different depending upon the technological level of the hospital. Results show that hospitals with more advanced CS contained their costs better. However, the latter effect of advanced CS is lower in hospitals with a greater endowment of high technology. Results suggest that health authorities should support the development of CS, particularly in high-tech hospitals, which are usually larger and more complex hospitals that tend to accumulate a greater portion of NHS hospital sector expenditure.
\end{abstract}

Keywords: Cost accounting systems; Hospital costs; Cost control; Management information systems; Technology, high-cost; Public hospitals. 


\section{Introduction}

At an international level health policy makers face an environment involving pressures to contain costs [1]. This explains the growing interest with respect to the calculation of health care costs [2,3] and, particularly, the cost systems (CS) used in hospitals [3-6]. Management health care literature suggests that the cost information provided by an effective CS facilitates management by clinicians, improves accuracy in the calculation of the price of services and can be used by managers for benchmarking; all of which could typically result in better cost containment and cost management [3-11]. Accordingly, many European countries have introduced standardized (sometimes mandatory) CS in at least a sample of hospitals, which present different characteristics such as costing methodology or the level at which costs are reported. While the main driver for the development of these standardized CS has been the setting of prices for hospital funding systems, the use of cost data to enable operational process and cost management has become a pressing issue for policy makers and providers [7]. In fact, in current competitive reimbursement environments, there are indications that some providers are now implementing more advanced CS [4]. In parallel, hospitals try to improve their performance with respect to technical expertise and patient interactions by making significant investments in high technology [12]. Furthermore, recent research supports the idea of studying the financial effects of cost control systems jointly with technology given the necessary integration of data from both systems for maximizing the performance of CS [13].

Despite the above, only a few studies have examined the relationship between alternative CS and the hospital costs in large samples of hospitals [9-11]. In general, these papers have not found a significant relationship between the design of CS and operating costs. Moreover, their methodology of research, using cross-section data, may be subject to reverse causality or endogeneity. Hence the CS choice could be either the cause or the result of the hospital's cost performance. On the other hand, these studies do not consider explicitly the technological level of the hospital, which makes them unable to verify if high technology and CS are complementary in terms of cost containment $[12,13]$.

In this paper, we try to address the aforementioned issues. Using the data of 242 hospitals of the Spanish National Health Service (NHS), we analyse via a difference-in differences approach the determinants of cost per adjusted patient day for the period 20102013 considering the effect of advanced CS on hospital costs and focusing on the comparison 
of hospitals with different technological levels. Because the implementation of CS is promoted by regional health authorities it is relatively exogenous with respect to each hospital and enables us to address the endogeneity problem.

While this study also builds on earlier papers that analyse the relationship between CS type and hospital costs, our primary contribution is to assess the effect of a regional health public policy i.e., the level of development of the standardized CS on hospital operating cost. A second contribution is that we analyse the complementarity between high technology and CS with respect to cost containment. Since NHS hospitals allocate a portion of their budget to the implementation and development of CS, it is important that health authorities systematically evaluate the effectiveness of investing in alternative CS for decision-making processes.

Results show that hospitals with more advanced CS contained their cost better, although this containment is lower in hospitals with a greater endowment of high technology. This indicates that in the period analysed, more advanced standardized CS facilitated cost containment objectives. Results suggest that health authorities should support the development of CS, particularly in high-tech hospitals, which are usually represented by larger and more complex hospitals, precisely those that accumulate the greatest portion of NHS hospital sector expenditure.

\section{Literature review}

\subsection{Development level of CS design}

The design of CS implies taking a series of decisions such as [14]: (1) which costs to include in the products; (2) at what level of detail should direct costs be assigned to the products; (3) the number and type of indirect cost centres, or cost pools, used to assign indirect costs to the products; (4) types of cost drivers (according to their degree of precision) used to assign indirect costs. Hence, in a hospital CS is referred to as more complex or developed when defining more specific cost objects, cost pools or cost drivers [15]. Furthermore, the design of an appropriate CS should also consider the organisational context and the purpose behind the information on costs [16].

In the case of hospitals, the debate concerning CS design has centred foremost on the level of detail with which to assign direct costs to patients, distinguishing between CS per 
patient (otherwise denominated as bottom-up or clinical cost) and CS per process or DRG (Diagnosis-Related Groups) (also called top-down), although in practice, it is usual to find mixed CS [5]. In the context of standardized CS in Europe, some countries, e.g., Germany, The Netherlands, and Denmark, have introduced patient-level costing, following a predominantly bottom-up activity-based costing approach. Other countries, e.g., England and Ireland, are currently moving from a predominantly top-down volume-based costing approach towards bottom-up activity-based costing [7].

In fact, a certain theoretical consensus exists which suggests that more advanced CS, at the patient level, offer more disaggregated and precise information which serves to improve decision-making and efficiency. Specifically, it sustains that these advanced CS are more useful because they allow the clinician to link clinical outcomes with costs in a meaningful way, thereby facilitating their engagement with management [7,17]; provide solid costing information for calculating the prices of services and supporting budget negotiations [18]; and managers can use information provided by them to redesign treatment processes more efficiently (benchmarking) [5].

\subsection{Empirical evidence of the relationship between the design of CS and financial} performance

Despite the comments of the foregoing section, the empirical research regarding the effect of more developed CS on financial performance is modest.

Some of these works are in-depth case studies that analyse the implementation of advanced CS, such as costing by patient or Activity Based Costing (ABC) in a single hospital $[18,19,20]$. Although this research reveals evidence of the influence which the information provided by CS has on resource allocation and those working practices aimed at reducing costs, none of the papers actually quantify the impact of CS on financial performance.

Other quantitative type studies, investigate the effect on cost reduction of a specific cost accounting practice such as the cost comparison between different clinicians performing the same procedure $[17,21]$, but obtain contradictory results.

Using a large sample of hospitals only a few papers analyse the influence of the CS type on real cost. Most of them collect the information about the CS characteristics from surveys. For example, Lawrence [9], using a sample of 499 US hospitals, does not find any relationship between CS type (CS per patient or CS per department) and cost per case, with 
the exception of the cost of capital per case, which was greater in those hospitals using CS per patient. In another study for a sample of 277 US hospitals, Pizzini [10] does not reveal any association between the characteristics of the CS and the cost per case, although the author finds that the level of detail of the information from the CS is associated with an improvement in administrative costs. In a more recent paper, Macinatti and Anessi-Pessina [11], using a sample of 131 Italian public health organisations, do not find statistical significance between CS design and financial performance. All the aforementioned studies use cross-sectional data and some of them acknowledge that the research design used may be subject to reverse causality or endogeneity. Logically, these works claim that future research should focus on longitudinal studies in order to observe causal linkages between variables over longer periods of time.

In this study, we try to address the previous issue. For this purpose, we base our analysis on a prior research of the impact of Spanish standardized CS on hospital cost where, using a sample of 170 acute NHS hospitals, an indirect relation between variation in unit cost and level of development of the CS was observed [22]. In the present paper, we focus on the comparison between hospitals with different technological levels. Given that maximizing the performance of advanced CS requires integrating the data of technology services provided to the patient $[12,13]$ into the CS, this comparison will provide new insight into the analysis of the usefulness of standardized CS at a hospital level. High-tech hospitals that deal with a variety of different types of patients are more complex organizations which have a greater need for systems of coordination and control [23] and as such probably experience more difficulties when integrating the information required by the CS [13].

With previous observations in mind we have designed a study to answer the following questions:

1. Do advanced standardized CS contribute towards the control of unit costs in hospitals?

2. Are there differences in the effect of advanced standardized CS depending upon the hospital's technological level? 


\section{Research method}

The Spanish NHS offers an appropriate framework for researching the aforementioned questions for two reasons.

First, it is characterised by a high level of decentralisation where the jurisdiction over health care is split into seventeen Regional Health Services (RHS). RHS are the organism created by Spain's Autonomous Communities (Spanish Regional Governments) to manage health care responsibilities and it is they that decide which type of CS should be implemented in the hospitals under their supervision. These CS present different characteristics, collected from the report Analysis of Analytical Accounting Systems in the NHS Hospitals for the year 2010 [24]. The characteristics of CS depend on various factors such as the number of years of health care management autonomy or the push to the development of CS imposed by the RHS according to the health policy makers in power. For example, in 2010 only five RHS had introduced cost per patient but the rest consider it as a goal to be achieved. This setting allows us to examine the effect on hospital unit cost of the alternative CS whose implementation is encouraged by regional health authorities, something which is relatively exogenous with respect to each hospital which enables us to address endogeneity problems.

Second, between 2010 and 2013 the Spanish Government adopted the main measures for containing health expenditure as a result of the crisis [25]. Thus, it may in fact prove to be a period during which health managers focused on cost control and used the information from CS to a greater extent. Prior research points that as environmental uncertainty increases decision makers seek to minimize said uncertainty through the use of additional information for planning and control [26]. Therefore, the use of management controls such as CS may increase as budget restrictions increase.

\subsection{Sample and data}

For the empirical analysis we have constructed a database of Spanish NHS hospitals using the microdata of Specialised Healthcare Centre Statistics published by the Ministry of Health, Social Policy and Equality (SIAE) [27]. Of the 764 hospitals included in the Statistics for 2013, 453 make up the NHS hospital network. The monetary data has been deflated in accordance with the evolution of the Consumer Price Index and is expressed in Euros (at 2013 purchasing power). 
Together with the hospital microdata, we have considered as an additional data source the report, previously mentioned, Analysis of Analytical Accounting Systems in the NHS Hospitals [24], which collects the different characteristics and costing methodologies for the year 2010 of the standardized CS implanted by the Regional Health Services (RHS). This report has not been updated after 2010. So, in this study we have to consider that the characteristics of the CS are maintained during the years 2010 to 2013. Thus, since CS are expensive to procure and generally have an associated implementation period, it is unlikely that hospitals drastically changed their CS during the period considered [12].

A sample of 242 hospitals is used corresponding to fourteen RHS. The hospitals of three RHS (Catalonia Health Service, Navarra Health Service, Health Service of Castilla-La Mancha) were omitted from the sample given that no information was available regarding their CS.

\subsection{Variables}

The dependent variable is the unit cost measured as cost per adjusted patient day. The numerator is calculated as the sum of all the hospital's operating costs with the exception of depreciation given the possible imprecision and subjectivity of its calculation [24]. The denominator is the number of adjusted patient days, in Spain denominated 'unidades ponderadas de actividad' or UPA (weighted health care unit). The UPA is the unit of health care production measured, according to the methodology used by the SIAE, in weighted days of inpatient stays based on the complexity of the activities performed in each area (medicine, several types of surgery, outpatient visits and other hospital services) [27].

Based on previous research [16,28] we measure the level of development of the standardized CS through an index for each RHS defined as a function of the following dimensions, indicative of more developed CS: (a) Level of detail or disaggregation of the information available [9-11]; (b) Different types of cost centres [29]; (c) Costs included in the product (as well as staff, current goods and services and health assistance agreements), given that if more cost categories are included in the product we can consider the CS as more complex [16]; (d) Methodology of the cost imputation, considering the reciprocal method as the most precise because it permits a reflection of all the mutual services existing between centres [29]. The index is defined in Table 1 and the detail of their calculation is available in a previous study [22] and as Supplementary material. From this index, we have constructed a dummy variable, advanced cost system (ACS), that indicates if the hospital has an advanced 
CS $(A C S=1)$ or not $(A C S=0)$. We consider CS as advanced if the level of development of the CS is equal or above the median of the index $(A C S=1)$, and non-advanced if the level of development of the CS is inferior to this reference $(A C S=0)$. Our data comprises 167 hospitals with an advanced CS and 75 hospitals with non-advanced CS.

We measure the endowment of high technology as a percentage of the available high technologies from a total of twelve (Table 1). We have established two groups of hospitals according to their endowment of high technology, represented by the variable technological endowment group (TEG). We consider the hospital as having high technology if it has a high technology endowment value equal to or above the median of this variable $(T E G=1)$. Likewise, it has low technology if the technology endowment value is inferior to the reference value $(T E G=0)$.

Moreover, based on the previous literature, we consider additional variables as possible determinants of the evolution of unit cost: average cost of personnel [30], workers per 100 beds [30], occupancy rate [9,30,31], in-hospital mortality rate [32], teaching status [33] and acute. The hospital size (by the number of beds) and the complexity of the cases treated $[9,10]$ are represented in this paper by the variables endowment of high technology and teaching status [34].

Table 1 shows how each of the variables has been measured.

[Insert Table 1 about here]

Table 2 presents the average values of a stable sample of 242 NHS hospitals considered in 2010 and 2013, classifying the hospitals into two groups according to the level of development of their cost system $(A C S)$, and indicating the statistical differences applying a $t$ test of the difference in averages of the related samples. Into the sample $83.5 \%$ of the hospitals are acute and 68.2\% are teaching hospitals in 2013 (63.6\% in 2010).

[Insert Table 2 about here] 
The unit hospital cost decreased significantly in the period 2010-2013 for the group with an advanced CS. There is a significant reduction in labour cost per worker and an increase in staff in training per 100 beds in both groups.

\subsection{Econometric methodology}

We use a difference-in-differences (DD) methodology to estimate treatment effects comparing the previous and post-treatment differences in the unit cost (cost per adjusted patient day) of two groups: treatment group or hospitals that have an advanced CS against a control group with non-advanced CS [35].

We estimate two models, the first being the following:

$$
\text { Unit Cost }_{i}=\beta_{0}+\beta_{1} \text { period }_{i}+\beta_{2} A C S_{i}+\beta_{3} \text { period }_{i} x \text { ACS }_{i}+\sum_{k=1}^{7} \delta_{k} z_{k i}+e_{i}
$$

Unit Cost is the cost per adjusted patient day of hospitals. Period is a dummy variable indicating the baseline (period $=0$ if year=2010) and a follow-up (period $=1$ if year=2013). Additionally, the dummy variable ACS indicates the treatment and $z_{k i}$ represents the seven control variables: endowment of high technology, average cost of personnel, workers per 100 beds, occupancy rate, in-hospital mortality rate, teaching status (dummy) and acute (dummy).

We understand that $A C S$ is an exogenous variable since the level of development of the CS is not determined by the hospitals but by the managers and political authorities that manage the RHS.

The estimated coefficients have the following interpretation:

$\beta_{0}$ : Is the mean unit cost (outcome) for the control group at the baseline

$\beta_{0}+\beta_{1}$ : Is the mean unit cost for the control group in the follow-up

$\beta_{2}$ : Is the single difference between treated and control groups at the baseline

$\beta_{0}+\beta_{2}$ : Is the mean unit cost for the treated group at the baseline

$\beta_{0}+\beta_{1}+\beta_{2}+\beta_{3}$ : Is the mean unit cost for the treated group in the follow-up 
$\beta_{3}$ : Is the $\mathrm{DD}$ estimator that represents the average treatment effect

$\delta_{k}$ : represents the coefficients of the control variables

The second model, which is similar to the first one, incorporates the triple interaction between the dummy variables period, ACS and TEG.

$$
\begin{gathered}
\text { Unit Cost }_{i}=\beta_{0}+\beta_{1} \text { period }_{i}+\beta_{2} \text { ACS }_{i}+\beta_{3} \text { period }_{i} x A C S_{i}+\beta_{4} T E G_{i}+ \\
\beta_{5} \text { period }_{i} \times T E G_{i}+\beta_{6} A C S_{i} \times T E G_{i}+\beta_{7} \text { ACS }_{i} \times \text { period }_{i} \times T E G_{i}+\sum_{k=1}^{6} \delta_{k} z_{k i}+e_{i}
\end{gathered}
$$

The DD estimate for treatment effect in the group of hospitals with low technology is $\beta_{3}$ and the estimate for treatment effect in the group of high technology is $\beta_{3}+\beta_{7}$. Thus the treatment effect for both groups of technology differs by $\beta_{7}$, which is the coefficient of the triple interaction term, or the difference in difference in differences (DDD) estimate.

\section{Results}

The results were obtained with the program STATA 14.2. The two models are estimated with robust standard errors using ordinary least squares (OLS) and panel data with fixed effects (FE) and random effects (RE) (see Table 3). The Hausman test supports the estimation of fixed effects in model $1(\mathrm{p}<5 \%)$ and random effects in model $2(\mathrm{p}>5 \%)$.

\section{[Insert Table 3 about here]}

In model 1, the treatment effect (period $x A C S$ ) is negative and significant in the three estimates made. The effect of an advanced cost system $(A C S=1)$ is quantified by a reduction of approximately $30 €$ in the unit cost for the period analysed.

In general, in model 1, a direct relation appears to exist between unit cost and the condition of acute, the average personnel cost and the number of workers per 100 beds. The endowment of high technology has a positive and significant effect in OLS and RE, but this relation is no significant in FE. On the other hand, a negative relationship is observed between 
the unit cost and the occupancy rate. The teaching status only has a significant and positive effect in OLS. The in-hospital mortality rate shows no significant influence.

From the OLS estimation performed in the model 1, using the method of adjusted predictions [36], Figure 1 shows the unit cost for 2010 and 2013 according to the treatment $(A C S)$. It is observed that the group of hospitals that have an advanced CS presents a reduction in the unit cost estimated to be $5.4 \%$, while in the case of hospitals with a nonadvanced CS the unit cost increases by $0.4 \%$.

[Insert Figure 1 about here]

Predictions of the unit cost for 2010 and 2013 according to the ACS

In the model 2, the treatment effect in the group of hospitals with low technology $(T E G=0)$ is the coefficient of the interaction period $x A C S$, that is negative and significant in the three estimates made. The effect of an advanced cost system $(\mathrm{ACS}=1)$ is quantified in a reduction of approximately $54 €$ in the unit cost over the period analysed for the group of low technology. In the case of the group of high technology $(T E G=1)$, to evaluate the effect of the cost system we have to consider together the coefficients of the interaction period $x$ ACS and of the triple interaction period $x$ ACS $x$ TEG. Since the coefficient of the triple interaction is positive and significant, the effect of an advanced CS $(A C S=1)$ in the high-tech group $(T E G=1)$ is lower than in the case of the low-tech group. Specifically, the triple interaction coefficient is quantified at approximately $46 €$ (in the case of panel data), which means that the final effect of an advanced CS $(A C S=1)$ on the unit cost for the high technology group is lower, with an approximate reduction of $8 €(54-46)$. These results suggest that the more developed CS present difficulties in managing costs in high-tech hospitals.

The coefficient of the interaction period $x$ TEG is negative and significant in the three estimates made in model 2, what seems to indicate that the high technology has contributed to reducing the unit cost between 2010 and 2013.

In general, similar to model 1, results of model 2 show a direct relation between unit cost and the condition of acute, the average staff cost and the number of workers per 100 beds. On the other hand, a negative relationship is observed between the unit cost and the occupancy rate. 
Similarly to model 1, from the OLS estimation performed in model 2, Figure 1 shows the unit cost for 2010 and 2013 according to the treatment (ACS) for the two groups of technology endowment. It is observed that the group of low technology hospitals with an advanced CS presents a reduction in the unit cost estimated at $6.3 \%$, while in the case of hospitals with a non-advanced CS the unit cost increases by $4.4 \%$. In the case of high-tech hospitals, there is a reduction in the unit cost both in those hospitals with an advanced CS $(4.3 \%)$ and with non-advanced CS (2.8\%).

Concerning the technology, we want point out that although in model 1 technology is positively associated with unit cost, model 2 shows that, from 2010 to 2013, the high technological level $($ TEG $=1)$ has contributed to the reduction of unit cost.

Also with respect to high technology, as a robustness test, we have replicated the two models measuring the endowment of high technology through a Saidin Index [12,37] created using the set of 12 technologies cited in Table 1, the results being similar to those shown in Table 3.

\section{Discussion}

In a scenario involving increasing health care costs and budget restrictions, policy makers need to identify the most effective measures that contribute to long-term cost containment [1]. Using the data of Spanish NHS hospitals this paper analyses the determinants of the cost of adjusted patient day for the period 2010-2013 considering the effect of a regional health public policy, such as the implementation of more advanced standardized CS, on the hospital costs. Our study evidences that more refined costing techniques can assist cost efficiency objectives.

Our results show that an advanced CS contributes to the reduction of the unit cost in the period 2010-2013. These results differ from most prior research which did not find significant relationships between CS design and operating costs [9-11]. This finding could be attributed to the fact that in this study we consider a period of four years, which would allow capturing the benefits derived from the use of CS over time. Additionally, we have considered a period which subjected Spanish NHS hospitals to the most stringent budgetary constraints derived from the economic crisis. Thus, our result would be consistent with the hypothesis that managers focus on cost information from CS to contain cost in response to regulatory external shocks [26]. It is in this context where advanced CS may demonstrate their 
usefulness because potentially RHS can identify less efficient hospitals and make decisions about them. It seems that RHS have become better able to compare different service providers and to use the information in the negotiation of budgets, thereby gaining more control over the costs of specialized health care [18].

On the other hand, this result supports the idea that CS established by health authorities not only serves to fulfil legal requirements or produce data for external reporting but would additionally enable managerial decision-making. In the context studied, while being unsatisfied about the standardized CS and viewing it as nonoptimal, hospitals may still consider the system sufficient and therefore use it for their decision-making processes [15].

Our results also suggest that the effect of advanced CS on unit cost is reduced in hospitals with greater endowments of high-tech equipment. Here, we have to point out that if we interpret in isolation the effect of high technology we observe that it has contributed to reducing unit cost, supporting previous studies indicating that medical technology can also help reduce costs via increases in productivity, greater efficiency in processes or substitution of relatively more costly procedures $[38,39]$. However, when we analyse the effect of high technology endowment and advanced CS in conjunction, we find that more advanced CS present difficulties in managing costs in high-tech hospitals, resulting in a lower reduction of costs than in hospitals with low technology. This result would appear logical, presumably because the former are usually the largest hospitals well equipped to deal with more complex case-mix and more medical specialties, so they are more complex organizations which have a greater need for systems of coordination and control [23]. In this setting, integration between different technologies can be more difficult, hindering the complementarity necessary to capture all the potential benefits of the advanced CS. It should be noted that CS in the health care sector are often designed to only fulfil legal requirements; therefore the culture and the resources within a hospital may not yet be established to integrate different system applications and various types of clinical and non-clinical performance information $[15,40]$.

As expected, the variation in average cost per worker and the variation of workers per bed are associated directly with the evolution of unit cost, which reflects the impact of the cuts undertaken by the Spanish government in the period of the crisis.

Also as we expected, the increase in activity, represented by the occupancy rate, contributes to the reduction in unit cost, in line with the results obtained in previous research [31]. Likewise, in-hospital mortality rate shows no significant influence on cost in line with 
prior studies on hospital efficiency that failed to reveal a trade-off between quality and efficiency [32].

\subsection{Implications for health policy}

Health policy makers and hospital managers can benefit from insights on the relationship between investment in CS and technology, and cost outcomes. Installing more developed CS and investing in high technology are measures which require significant upfront financial investment and are technically demanding [1]. Our results suggest that these investments may help hospitals achieve the goal of cost containment. We find that, in isolation, both advanced CS and endowment of high technology are associated with a reduction in operating unit cost from 2010 to 2013. Nevertheless, advanced CS can see their potential reduced in high-tech hospitals, probably due to the integration difficulties of clinical and non-clinical (economic-financial, accounting) information in more complex settings. This finding indicates that health policy makers and hospital administrators should promote investments in developing CS, but keep in mind the necessity of their integration with clinical technology [12]. It should be noted that in the sample analysed high-technology hospitals accumulated $83,5 \%$ of the total expenditure in the year 2013 .

There are certain instruments for policy makers and regulators in order to facilitate the development and use of CS. This is the case of costing guidance for the purpose of provider cost reporting [7]. In some countries (e.g., Spain, Germany, France, and The Netherlands), hospitals have to demonstrate adherence to such guidance through external audit checks if they wish to use cost samples for calculating DRGs costs. The DRG data are then reported to the government and regulators, usually annually. Thus, if hospitals want to influence price setting by contributing their costs per case, they are forced to adhere to defined standards. Other possible measures to encourage the improvement of CS would be, for example, to make a small part of the budget dependent on the collection of cost data [5] or disclosure regulation in the form of state/region-level price transparency websites [41].

\subsection{Limitations}

The empirical study has the limitation of using only publicly available information, which means that we have analysed the hospital data assuming that all of them employ a CS with a similar level of development, dependent upon the RHS to which they belong. In order to give robustness to the results obtained, data on the characteristics and use of CS 
implemented in each hospital should be expanded and the explanatory variables used should be explored further. It is possible to use a more granular scale to measure the level of development of CS, including the level of CS integration and the time lag since CS implementation [13]. For example, it is possible to refine empirically the definition of advanced CS including other characteristics that could not be measured in this study: degree of precision of the cost drivers; classification of costs according to behaviour; frequency and breadth of cost-report distribution; number and type of variances calculated; level of satisfaction that users have with information from CS; and use of the information from the CS $[10,11]$. This may provide a more in-depth knowledge as to the effect of CS on hospital performance.

Future research could consider the use of surveys to obtain data about CS and the inclusion of additional explanatory variables such as case-mix indices and other quality indicators (e.g. readmission rate, surgical outpatient rate) by hospital.

\section{Conclusions}

We can conclude that during a period of more restrictive budget constraints in Spanish NHS hospitals, the more advanced standardized CS have contributed to cost containment. In those hospitals with greater endowments of high-tech equipment the contribution of advanced CS was lower than in the low-tech hospitals, which suggests that these CS present difficulties in terms of the cost management in high-tech hospitals.

Given that high-tech hospitals usually accumulate the greater part of the expenditure in the NHS hospital sector, our results indicate that health authorities should establish measures which favour the development of CS in these types of hospitals in order to improve efficiency.

\section{References}

[1] Wenzl M, Naci H, Mossialos E. Health policy in times of austerity-A conceptual framework for evaluating effects of policy on efficiency and equity illustrated with examples from Europe since 2008. Health Policy (2017), http://dx.doi.org/10.1016/j.healthpol.2017.07.005 
[2] Busse R, CShreyögg J, Smith PC. Variability in healthcare treatment costs amongst nine EU countries - results from the HealthBASKET project. Health Economics 2008;17(S1):S1-S8.

[3] Kaplan RS, Porter ME. How to solve the cost crisis in health care. Harvard Business Review 2011;89(9):46-52.

[4] Keel G, Savage C, Rafiq M, Mazzocato P. Time-driven activity-based costing in health care: A systematic review of the literature. Health Policy (2017), http://dx.doi.org/10.1016/j.healthpol.2017.04.013

[5] Tan SS, Serden L, Geissler A, et al. DRGs and cost accounting: which is driving which? In: Busse R, Geissler A, Quentin W, Wily M, editors. Diagnosis-Related Groups in Europe: moving towards transparency, efficiency and quality in hospitals. Berkshire: Open University Press, McGraw-Hill Education; 2011.

[6] Vogl M. Improving patient-level costing in the English and the German 'DRG' system. Health Policy 2013;109(3):290-300.

[7] Chapman C, Kern A, Laguecir A. Costing practices in healthcare. Accounting Horizons 2014;28(2):353-364.

[8] Busse R, Quentin W. Moving towards transparency, efficiency and quality in hospitals: Conclusions and recommendations. In: Busse R, Geissler A, Quentin W, Wily M, editors. Diagnosis-Related Groups in Europe: moving towards transparency, efficiency and quality in hospitals. Berkshire: Open University Press, McGraw-Hill Education; 2011.

[9] Lawrence CM. The effect of ownership structure and accounting system type on hospital costs. Research in Governmental and Nonprofit Accounting 1990;6:35-60.

[10] Pizzini MJ. The relation between cost-system design, managers' evaluations of the relevance and usefulness of cost data, and financial performance: an empirical study of US hospitals. Accounting, Organizations and Society 2006;31(2):179-210.

[11] Macinati MS, Anessi-Pessina E. Management accounting use and financial performance in public health-care organisations: Evidence from the Italian National Health Service. Health Policy 2014;117(1):98-111. 
[12] Sharma L, Chandrasekaran A, Boyer KK, McDermott CM. The impact of health information technology bundles on hospital performance: An econometric study. Journal of Operations Management 2016;41:25-41.

[13] Maiga AS, Nilsson A, Jacobs FA. Assessing the interaction effect of cost control systems and information technology integration on manufacturing plant financial performance. The British Accounting Review 2014;46(1):77-90.

[14] Fisher JG, Krumwiede K. Product costing systems: Finding the right approach. Journal of Corporate Accounting \& Finance 2012;23(3):43-51.

[15] Cardinaels E, Roodhooft F, Van Herck G. Drivers of cost system development in hospitals: results of a survey. Health Policy 2004;69(2):239-252.

[16] Krumwiede KR, Suessmair A, MacDonald J. A framework for measuring the complexity of cost systems (August 17, 2013). AAA 2014 Management Accounting Section (MAS) Meeting Paper. Available at: SSRN: http://ssrn.com/abstract=2311720 or http://dx.doi.org/10.2139/ssrn.2311720.

[17] Eldenburg L. The use of information in total cost management. Accounting Review 1994;69(1):96-121.

[18] Lethonen T. DRG-based prospective pricing and case-mix accounting - Exploring the mechanisms of successful implementation. Management Accounting Research 2007;18(3):367-395.

[19] Lowe A. Accounting in health care: some evidence on the impact of casemix systems.The British Accounting Review 2000;32(2):189-211.

[20] Eldenburg L, Soderstrom N, Willis V, Wud A. Behavioral changes following the collaborative development of an accounting information system. Accounting, Organizations and Society 2010; 35(2):222-237.

[21] Evans III JH, Hwang Y, Nagarajan NJ. (2001). Management control and hospital cost reduction: additional evidence. Journal of Accounting and Public Policy 2001;20(1):7388.

[22] García-Cornejo B, Pérez-Méndez JA. Sistemas de costes y gasto hospitalario. Gaceta Sanitaria (2017), http://dx.doi.org/10.1016/j.gaceta.2017.06.002 
[23] Chenhall RH. Management control systems design within its organizational context: findings from contingency-based research and directions for the future. Accounting, Organizations and Society 2003; 28(2):127-168.

[24] Instituto de Información Sanitaria. Análisis de los sistemas de contabilidad analítica en los hospitales del SNS [Analysis of the analytical accounting systems of the NHS hospitals]. Año 2011. Vol. I. Madrid: Ministerio de Sanidad, Servicios Sociales e Igualdad. Available at: https://www.msssi.gob.es/estadEstudios/estadisticas/docs/Informe_SCA_hospitalarios_ en_SNS_WEB.pdf [accessed 29.08.17].

[25] Bandrés E, González R. La reducción del gasto sanitario en España durante la crisis. Cuadernos de Información Económica 2015; 248:37-48.

[26] Hill NT. Adoption of costing systems in US hospitals: An event history analysis 19801990. Journal of Accounting and Public Policy 2000;19(1):41-71.

[27] Ministry of Health, Social Policy and Equality. Subdirección General de Información Sanitaria e Innovación. Estadística de Centros de Atención Especializada [SIAE]. Resultados año 2013. Madrid: Ministerio de Sanidad, Servicios Sociales e Igualdad. Available

at: https://www.msssi.gob.es/estadEstudios/estadisticas/estHospiInternado/inforAnual/hom eESCRI.htm [accessed 29.08.17].

[28] Al-Omiri M, Drury C. A survey of factors influencing the choice of product costing systems in UK organizations. Management Accounting Research 2007;18(4):399-424.

[29] Subdirección General de Información Sanitaria e Innovación. Guía de recomendaciones para la obtención homogénea de costes de hospitalización en el SNS. [Publicación en Internet]. Madrid: Ministerio de Sanidad, Servicios Sociales e Igualdad; 2013. Available at:

http://www.msssi.gob.es/estadEstudios/estadisticas/docs/REC_OBT_HOM_COST_HO SPIT_SNS.pdf [accessed 29.08.17]

[30] Wu VY, Shen YC, Yun MS, Melnick G. Decomposition of the drivers of the US hospital spending growth, 2001-2009. BMC Health Services Research 2014;14(1):1-8.

[31] Puig J. La función de costes hospitalarios. Estudio de 151 hospitales. Gaceta Sanitaria 1988;5(2):68-72. 
[32] Tiemann O, Schreyögg J, Busse, R. Hospital ownership and efficiency: a review of studies with particular focus on Germany. Health Policy 2012;104(2):163-171.

[33] Sloan FA, Feldman RD, Steinwald AB. Effects of teaching on hospital costs. Journal of Health Economics 1983;2(1):1-28.

[34] Vitaliano M. On the estimation of hospital cost functions. Journal of Health Economics 1987;6(4):305-318.

[35] Wooldridge JM. 2002. Econometric analysis of cross section and panel data. Cambridge, Massachusetts: MIT Press; 2002. pp. 129-132.

[36] Williams, R. Using the margins command to estimate and interpret adjusted predictions and marginal effects. The Stata Journal 2012;12(2):308-331.

[37] Spetz J, Maiuro LS. Measuring levels of technology in hospitals. The Quarterly Review of Economics and Finance 2004;44(3):430-447.

[38] Sorenson C, Drummond M, Khan BB. Medical technology as a key driver of rising health expenditure: disentangling the relationship. ClinicoEconomics and Outcomes Research: CEOR 2013;5:223-234.

[39] PricewaterhouseCoopers. Aportación de valor de las tecnologías en el sector sanitario 2014. Available at: http://www.pwc.es/es/publicaciones/sectorpublico/assets/tecnologias-sector-sanitario.pdf [accessed 10.10.16].

[40] Escobar-Rodríguez T, Escobar-Pérez B, Monge-Lozano P. Technical and organisational aspects in enterprise resource planning systems implementation: lessons from a Spanish public hospital. Enterprise Information Systems 2014;8(5):533-562.

[41] Labro E, Stice-Lawrence L. Updating accounting systems: Long-Run evidence from the healthcare $\quad$ sector. $2016 . \quad$ Available at: http://msb.georgetown.edu/sites/default/files/labro-stice.pdf [accessed 11.06.17]

[42] Instituto Nacional de la Salud (INSALUD). GECLIF. Gestión Clínico-Financiera y coste por proceso. Madrid: Ministerio de Sanidad y Consumo, Subdirección General de Coordinación Administrativa; 2001. Available at: http://www.ingesa.msssi.gob.es/estadEstudios/documPublica/pdf/geclif2000.pdf [accessed 10.07.16]. 
Model 1

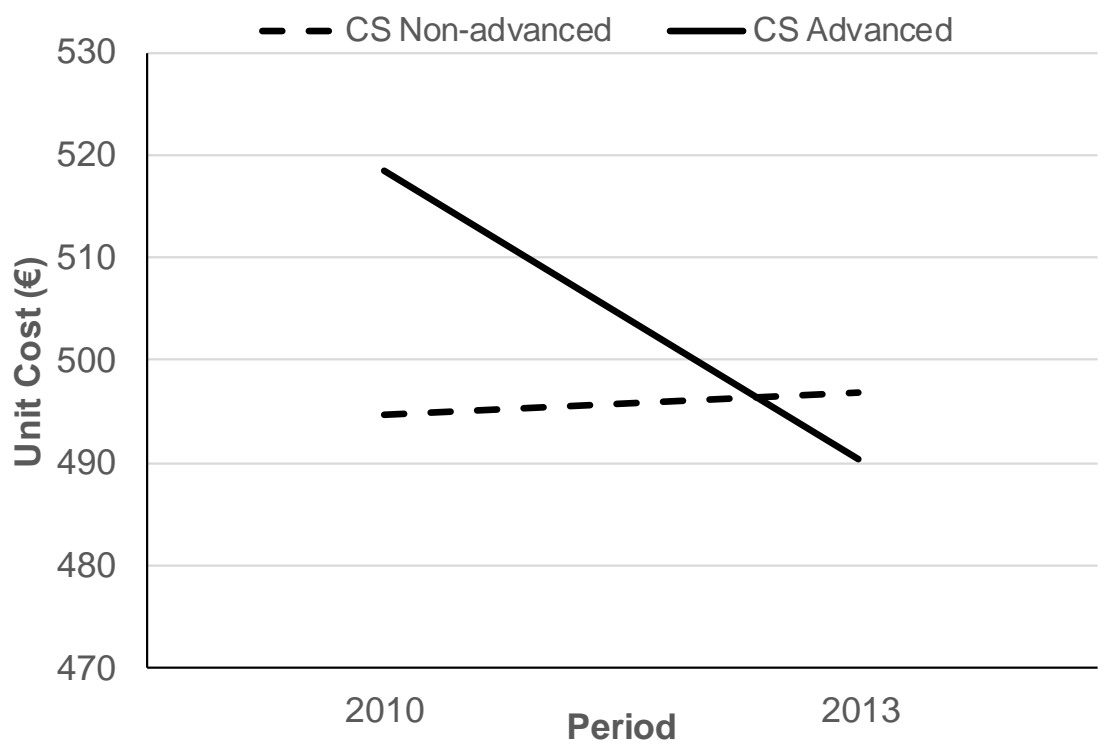

Model 2 - Low technology hospitals

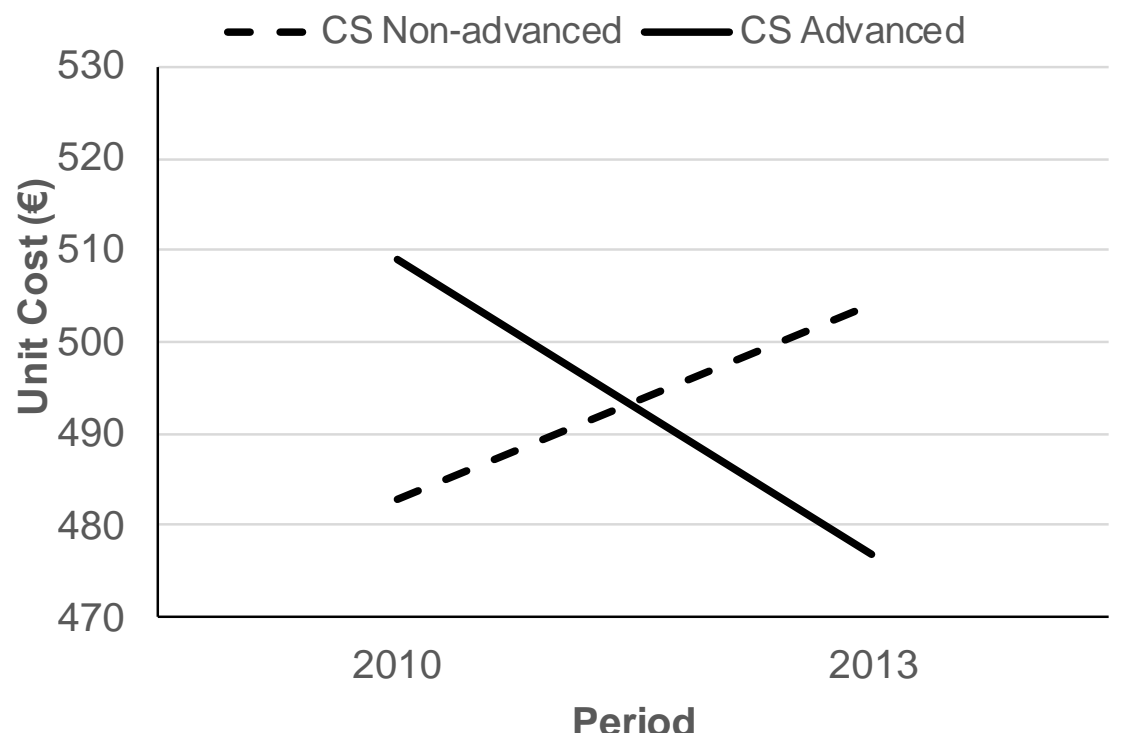

Model 2 - High technology hospitals

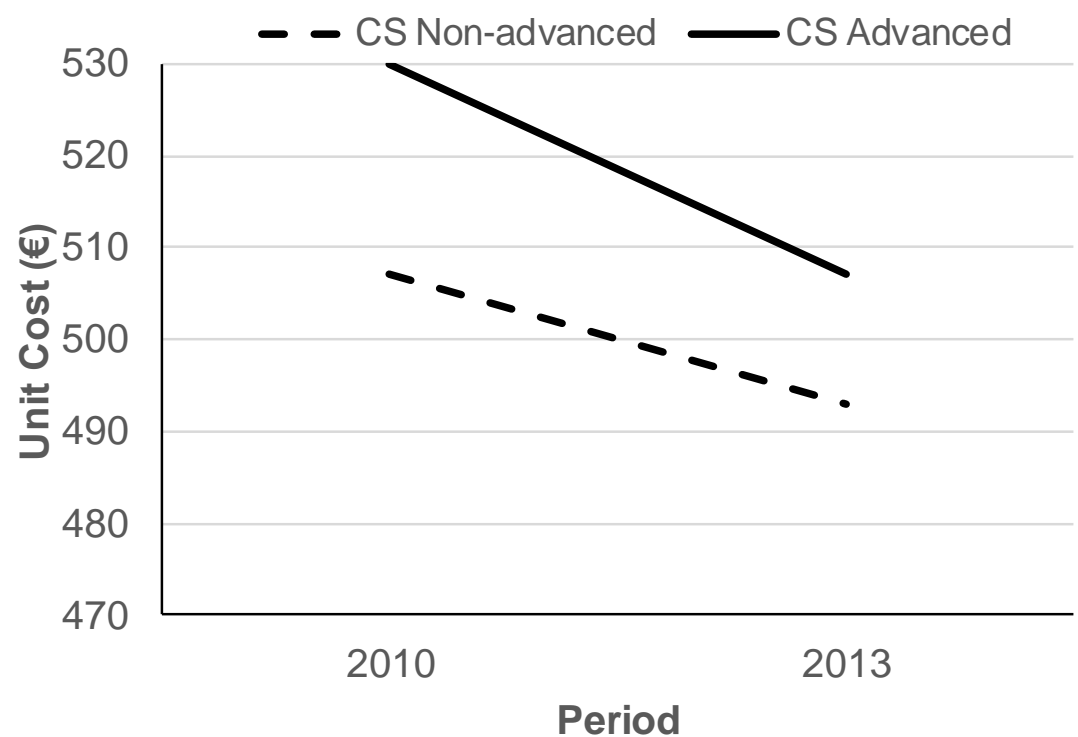




\section{Table 1}

Description of the variables

\begin{tabular}{ll}
\hline Variables & Definition \\
\hline $\begin{array}{l}\text { Cost per adjusted patient day }= \\
\text { Cost per UPA } \text { a }(\mathrm{UPA})\end{array}$ & (Total operating cost - Depreciation) / Adjusted patient days or UPAs \\
$\begin{array}{l}\text { Level of development of standardized cost- } \\
\text { accounting system }(\mathrm{CS})\end{array}$ & $\begin{array}{l}\text { Index of the level of development of the standardized CS implanted by the different } \\
\text { Regional Health Services, which take values between } 0 \text { and } 100 \text { according to the } \\
\text { number of characteristics }\left(\mathrm{C}_{\mathrm{i}}\right) \text { fulfilled by the CS }\end{array}$
\end{tabular}

Level of detail of the information, that considers four characteristics: Centre of responsibility $\left(\mathrm{C}_{1}\right)$, Line of activity $\left(\mathrm{C}_{2}\right)$, Process $\left(\mathrm{C}_{3}\right)$, Patient $\left(\mathrm{C}_{4}\right)$

Number of types of cost centres, that takes into account seven characteristics: Structural $\left(\mathrm{C}_{5}\right)$, Intermediate $\left(\mathrm{C}_{6}\right)$, Final $\left(\mathrm{C}_{7}\right)$, Intermediate-Final $\left(\mathrm{C}_{8}\right)$, Assignation auxiliaries $\left(\mathrm{C}_{9}\right)$, Analytical operating units $\left(\mathrm{C}_{10}\right)$, Other $\left(\mathrm{C}_{11}\right)$

Costs included (as well as staff, current goods and services and health assistance agreements), which considers: Depreciation $\left(\mathrm{C}_{12}\right)$, Current transfers $\left(\mathrm{C}_{13}\right)$

Imputation methodology: Reciprocal method $\left(\mathrm{C}_{14}\right)$

$$
\text { Index of development of the standardized } C S=\frac{\sum_{1}^{14} C i}{14} \times 100
$$

Advanced cost system (ACS)

Endowment of high technology

Technological Endowment Group (TEG).

Average cost of personnel (thousands of $€$ ) Workers per 100 beds

Occupancy rate $(\%)$

In-hospital mortality rate $(\%)$

Teaching status (dummy)

Acute (dummy)
Value 1 represents a level of development of the CS equal to or above the median and value 0 a level of development of the CS inferior to the median

Percentage of available high technologies from a total of 12 (linear accelerator, Digital Angiography, cobalt pump, densitometer, haemodialysis equipment, CAT scan, PET, Magnetic resonance, gamma camera, lithotripter, mammography, spectrometers)

Value 1 represents hospitals with a value in endowment of high technology equal to or above the median and value 0 with a value in endowment of high technology inferior to the median

Staff cost divided by the average number of workers

Number of workers multiplied by 100 and divided by the number of operational beds

Total stays divided by total days of operational beds

Total discharges by death divided by total discharges

Value 1 represents teaching hospitals and value 0 other hospitals

Value 1 represents acute hospitals (general and specialised) and value 0 other hospitals (medium and long stays, mental health and drug treatment)

\footnotetext{
${ }^{a}$ Unidad ponderada de actividad or UPA (Weighted Health Care Unit). The UPA is the unit of health care production measured, according to the methodology used by the SIAE (Specialised Healthcare Centre Statistics published by the Ministry of Health Health, Social Policy and Equality) in weighted days of inpatient stays based on the complexity of the activities performed in each area (medicine, several types of surgery, outpatient visits and other hospital services).

${ }^{\mathrm{b}}$ We assume that the characteristics are constant during the period 2010-13. The calculation of the index is available in a previous study [22] and as Supplementary material.
} 
Table 3

Results of the regression

Model 1 (484 observations)

Treatment group: hospitals with advanced cost systems

\begin{tabular}{|c|c|c|c|c|c|c|}
\hline & OLS & & $\begin{array}{c}\text { Panel Data } \\
\text { Fixed } \\
\text { Effects } \\
\end{array}$ & & $\begin{array}{c}\text { Panel Data } \\
\text { Random } \\
\text { Effects } \\
\end{array}$ & \\
\hline Period (dummy) & $\begin{array}{l}\text { Coef. } \\
2.087\end{array}$ & & $\begin{array}{l}\text { Coef. } \\
-1.567\end{array}$ & & $\begin{array}{l}\text { Coef. } \\
\quad-1.090\end{array}$ & \\
\hline ACS (dummy) & 23.789 & $*$ & a & & 21.223 & \\
\hline Period $x$ ACS & -30.302 & $* *$ & -30.703 & $* * *$ & -30.410 & $* *$ \\
\hline TEG (dummy) & --- & & --- & & --- & \\
\hline Period $\mathrm{x}$ TEG & --- & & --- & & --- & \\
\hline ACS $\times$ TEG & --- & & --- & & --- & \\
\hline Period $x$ ACS $x$ TEG & --- & & --- & & --- & \\
\hline $\begin{array}{l}\text { Endowment high technology } \\
(\%)\end{array}$ & 0.725 & $* * *$ & -0.621 & & 0.770 & $* * *$ \\
\hline Average staff cost $(000 €)$ & 5.351 & $* * *$ & 4.108 & $* * *$ & 4.756 & $* * *$ \\
\hline Workers per 100 beds & 0.057 & $* *$ & 0.108 & $* *$ & 0.062 & $* *$ \\
\hline Occupancy rate $(\%)$ & -1.251 & $* *$ & -2.752 & $* *$ & -1.460 & $* * *$ \\
\hline In-hospital mortality rate $(\%)$ & -0.062 & & -0.225 & & -0.082 & \\
\hline Teaching (dummy) & 29.377 & $* *$ & -22.644 & & 19.839 & \\
\hline Acute (dummy) & 132.368 & $* * *$ & a & & 135.273 & $* * *$ \\
\hline Constant & 155.506 & $* * *$ & 510.509 & $* * *$ & 202.811 & $* * *$ \\
\hline
\end{tabular}

Model 2 (484 observations)

Treatment group: hospitals with advanced cost systems according to two groups of technology endowment

\begin{tabular}{|c|c|c|c|c|c|}
\hline OLS & & $\begin{array}{c}\text { Panel Data } \\
\text { Fixed Effects }\end{array}$ & & $\begin{array}{c}\text { Panel Data } \\
\text { Random Effects }\end{array}$ & \\
\hline Coef. & & Coef. & & Coef. & \\
\hline 21.324 & & 18.311 & & 19.569 & \\
\hline 26.242 & & a & & 26.162 & \\
\hline-53.387 & $* * *$ & -54.605 & $* * *$ & -54.610 & $* * *$ \\
\hline 24.240 & & 4.740 & & 29.231 & \\
\hline-35.434 & $*$ & -37.544 & $* *$ & -37.213 & * \\
\hline-3.288 & & -20.852 & & -7.036 & \\
\hline 44.638 & $* *$ & 46.703 & $* *$ & 46.343 & $*$ \\
\hline --- & & --- & & --- & \\
\hline 0.005 & $* * *$ & 0.004 & $* * *$ & 0.005 & $* * *$ \\
\hline 0.059 & $* *$ & 0.103 & $* *$ & 0.061 & $* *$ \\
\hline-1.111 & $* *$ & -2.715 & $* *$ & -1.329 & $* *$ \\
\hline-0.015 & & -0.152 & & -0.039 & \\
\hline 35.734 & $* *$ & -26.774 & & 23.868 & \\
\hline 150.762 & $* * *$ & a & & 155.376 & $* * *$ \\
\hline 139.306 & $* *$ & 492.907 & $* * *$ & 185.021 & $* * *$ \\
\hline
\end{tabular}

ACS: Advanced cost system; TEG: Technology endowment group

${ }^{a}$ Omitted in Panel Data Fixed Effects (time invariant variable)

$*, * *, * * *$ Significant at $10 \%, 5 \%$ and $1 \%$ respectively. 
